\title{
Gold nanoelectrode ensembles for direct trace electroanalysis of iodide
}

\author{
Francisco C. Pereira ${ }^{c}$, Ligia M. Moretto ${ }^{a}$, Manuela De Leo ${ }^{\mathrm{a}}$, \\ Maria V. Boldrin Zanoni ${ }^{\mathrm{b}}$, Paolo $\mathrm{Ugo}^{\mathrm{a}, *}$ \\ ${ }^{a}$ Department of Physical Chemistry, Università Cà Foscari di Venezia, Calle Larga Santa Marta 2137, I-30123 Venezia, Italy \\ ${ }^{\mathrm{b}}$ Department of Analytical Chemistry, Institute of Chemistry, UNESP, 14800-900 Araraquara, SP, Brazil \\ ${ }^{\mathrm{c}}$ Department of Chemistry, Federal University of Rio Grande do Norte, 59072-970 Natal, RN, Brazil
}

Received 24 March 2006; received in revised form 18 May 2006; accepted 18 May 2006

Available online 27 May 2006

\begin{abstract}
A procedure for the standardization of ensembles of gold nanodisk electrodes (NEE) of $30 \mathrm{~nm}$ diameter is presented, which is based on the analytical comparison between experimental cyclic voltammograms (CV) obtained at the NEEs in diluted solutions of redox probes and CV patterns obtained by digital simulation. Possible origins of defects sometimes found in NEEs are discussed. Selected NEEs are then employed for the study of the electrochemical oxidation of iodide in acidic solutions. CV patterns display typical quasi-reversible behavior which involves associated chemical reactions between adsorbed and solution species. The main CV characteristics at the NEE compare with those observed at millimeter sized gold disk electrodes (Au-macro), apart a slight shift in $E_{1 / 2}$ values and slightly higher peak to peak separation at the NEE. The detection limit (DL) at NEEs is $0.3 \mu \mathrm{M}$, which is more than one order of magnitude lower than DL at the Au-macro (4 $\mu \mathrm{M})$. The mechanism of the electrochemical oxidation of iodide at NEEs is discussed. Finally, NEEs are applied to the direct determination of iodide at micromolar concentration levels in real samples, namely in some ophthalmic drugs and iodized table salt.
\end{abstract}

(C) 2006 Elsevier B.V. All rights reserved.

Keywords: Nanoelectrode ensembles; Iodide; Voltammetry; Edible salt; Ophthalmic drugs

\section{Introduction}

Iodine is a trace element present in seawater and sea products mainly in the form of iodide or iodate anions. For human beings, iodine is an essential component. It is required by the thyroid gland to produce two iodized hormones, thyroxine and triiodothyronine, which are used by the body during metabolism. The most common sources of iodine intake are table salt and seafood, but also other food can contain iodine, such as plants grown in iodine rich soils. However, in certain parts of the world the soil and hence the plants contain no iodine and such a deficiency in the diet can cause health problems [1,2]. Iodine enriched food products, in particular edible salt, are indeed commercialized to complete iodine supply and to avoid dangerous deficiencies. Iodized table salt is, typically, produced by the addition of potassium iodide or iodate to common table salt. The amount of iodine added to table salt or to other enriched

\footnotetext{
* Corresponding author. Tel.: +39041 2348503; fax: +390412348594.

E-mail address: ugo@unive.it (P. Ugo).
}

food should be monitored carefully since also excess iodine can be a source of serious health problems [3]. This caution extends also to pharmaceutical products, such as some iodide containing ophthalmic drugs used to contrast cataract [4,5].

The availability of reliable analytical methods to monitor the iodide content in food and drugs plays therefore a key role. Analytical methods to be applied for such analyses should be characterized by low detection limits, wide dynamic range and short response time. Various methods have been proposed to this aim such as spectrophotometry [6], ICP-MS [7], capillary electrophoresis [8,9], ion-chromatography and HPLC [10,11], the latter being probably the most widely used. By taking advantage of the electroactivity of iodide, electrochemical methods have been often applied to this goal. In order to reach low enough detection limits, the preconcentration of the analyte in the form of insoluble salts such as $\mathrm{HgI} / \mathrm{Hg}_{2} \mathrm{I}_{2}$ or $\mathrm{AgI}$ was exploited for developing cathodic stripping methods [12-17]. In particular, silver electrodes were applied both for cathodic stripping analyses [18-20] and as electrochemical detector for iodide determinations by ion-chromatography $[11,21,22]$. More recently, methods based on adsorptive accumulation [23], ion-pairing 
[24], ion-exchange at electrodes coated with clays [25] and polylysine [26], have been proposed. From the viewpoint of quick analytical control, e.g. in the environment or in foodstuff, directs methods (which could avoid a preconcentration step) might be preferable. It was shown that at low $\mathrm{pH}$ values, the electrochemical oxidation of dilute solutions of iodide at $\mathrm{Pt}$ [27-30] or $\mathrm{Au}$ $[31,32]$ electrodes is reversible, however, at iodide concentrations equal or higher than $1 \mathrm{mM}$ the process is complicated by the formation of adsorbed iodine films. The structure of the adsorbate layer was studied by surface-enhanced Raman spectroscopy on gold electrodes by Weaver and coworkers [33,34]. It was also shown [32] that iodide voltammetric patterns are improved when gold ultramicroelectrodes are used instead of "conventional" millimeter sized electrodes. Further improvements could be expected by a further miniaturization of the electrode system.

Recent researches [35-39] showed that the use of the socalled nanoelectrode ensembles (NEE) can improve the performances of electrochemical determinations thanks to dramatically improved signal to background current ratios with respect to other electrode systems [39]. NEEs are useful electrochemical tools for biosensors development [40,41], for the measurement of (high) charge transfer rate constants [35] and for solving adsorption related problems [36]. With respect to the latter issue, it was shown that operating in very diluted solutions of the analytes (thanks to the very low detection limits achievable at NEEs) it was possible to obtain diffusion-controlled responses even for molecules such as some phenothiazines [35] or redox proteins such as cytochrome $c$ [36], which can adsorb on electrode surfaces.

In the present work we examine the use of NEEs for the direct electroanalysis of iodide, focusing in particular on the possibility of performing the direct determination of trace amounts $(<1 \mu \mathrm{M})$ without preconcentration of the analyte. The method developed is applied finally to analyses in real samples such as iodized table salt and iodide containing drugs. In the first part of this study, the development of a reliable procedure for the standardization and selection of prototype NEEs to be used for the successful achievement of the above-described analytical purposes is examined.

\section{Experimental}

\subsection{Materials}

Polycarbonate filtration membranes (SPI-Pore, $47 \mathrm{~mm}$ filter diameter, $6 \mu \mathrm{m}$ filter thickness) with a nominal pore diameter of $30 \mathrm{~nm}$ and coated with the wetting agent polyvinylpyrrolidone were used as the templates to prepare the NEEs. Commercial gold electroless plating solution (Oromerse Part B, Technic Inc.) was diluted (40 times with water) prior to use.

The examined ophthalmic drugs were Facovit (Teofarma S.r.1, Italy) and Rubjovit (S.I.F.I. S.p.A, Italy). The declared composition of $100 \mathrm{~mL}$ of Facovit solution is, for active components: $100 \mathrm{mg}$ potassium iodide, $100 \mathrm{mg}$ rubidium iodide, $10 \mathrm{mg}$ propionate testosterone and $5 \mathrm{mg}$ riboflavin; excipients: monosodium phosphate dihydrate, disodium phosphate dihydrate, polysorbate 80 , (hydroxypropyl)methyl cellulose and benzalconium chloride. The composition of $100 \mathrm{~mL}$ of Rubjovit solution is: $800 \mathrm{mg}$ rubidium iodide, $1.2 \mathrm{~g}$ sodium iodide, $500 \mathrm{mg}$ calcium formate, $225 \mathrm{mg}$ sodium ascorbate, $200 \mathrm{mg}$ ascorbic acid and $250 \mathrm{mg}$ thiamine hydrochloride; excipients are boric acid, thiourea, phenol and lactose monohydrate.

For the analysis, the drug was at first diluted (1:10 for Facovit and 1:100 for Rubjovit) with $0.1 \mathrm{M} \mathrm{H}_{2} \mathrm{SO}_{4}$, then an aliquot of this solution was added to $20 \mathrm{~mL}$ of $0.1 \mathrm{M} \mathrm{H}_{2} \mathrm{SO}_{4}$ in the electrochemical cell.

The sample of commercially available iodized table salt (Salinen, Ebensee, Austria) was bought at a local grocery. It contained a declared value of $3 \mathrm{mg}$ of potassium iodide in $100 \mathrm{~g}$ of salt. The sample were prepared by dissolving $58.5 \mathrm{~g}$ (approximately equivalent to $1 \mathrm{~mol}$ of $\mathrm{NaCl}$ ) of the salt in $250 \mathrm{~mL}$ of sulphuric acid, $\mathrm{pH} 1.0$, and an aliquot of this solution (typically $400 \mu \mathrm{L}$ )

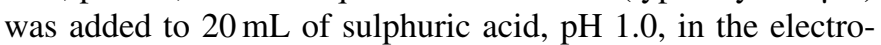
chemical cell.

(Ferrocenylmethyl)dimethylamine (Aldrich) was reacted with methyl iodide to form the quaternary ammonium iodide [42]. This was then converted to (ferrocenylmethyl) trimethylammonium hexafluorophosphate $\left(\mathrm{FA}^{+} \mathrm{PF}_{6}{ }^{-}\right)$using $\mathrm{AgPF}_{6}$.

All other reagents were of analytical grade and were used as received. Purified water was obtained using a Milli-Ro plus Milli-Q (Millipore) water purification system.

\subsection{Instrumentation}

All electroanalytical measurements were carried out at room temperature $\left(22 \pm 1^{\circ} \mathrm{C}\right)$ using a three-electrodes singlecompartment cell equipped with a platinum coil counter electrode and an $\mathrm{Ag} / \mathrm{AgCl}$ ( $\mathrm{KCl}$ saturated) reference electrode. All potential values are referred to this reference electrode. A CH660A apparatus controlled via PC by its own software was used for voltammetric measurements and for digital simulation.

\subsection{Preparation of the electrodes}

The nanoelectrode ensembles were prepared using the electroless plating procedure described previously [39] and following modifications [35].

Also the final assembly of the NEE (for obtaining electrodes handy for use in an electrochemical cell) followed substantially the previous method [39], however slightly modifying the final assembly in that, the copper tape which acts as electrical connection for the NEE was attached to the lower gold layer which completely covers one face of the membrane, instead of being attached to the upper gold layer as previously done [39]. This modification improved the electrical connection between copper and the NEE.

The geometric area, $A_{\text {geom }}$, of the NEE $\left(0.07 \mathrm{~cm}^{2}\right)$ is determined by the diameter $(3 \mathrm{~mm})$ of a hole punched in the insulating tape that covers the upper face (peeled) of the NEE.

Conventional "macro" gold electrodes, hereafter named "Aumacro" for brevity, were prepared from a golden glass plate (thickness $1 \mathrm{~mm}$ ) coated with nickel $80 \AA$, chromium $20 \AA$ and gold $3900 \AA$ on the outer surface. They were purchased from ACM France. The golden plate was cut into slides (ca. 
$2.5 \mathrm{~cm} \times 1.0 \mathrm{~cm}$ ) and the geometric area of the electrodes $\left(0.07 \mathrm{~cm}^{2}\right)$ was defined, as it was made for the NEE, by the diameter of a hole punched in a strip of insulating tape which covers all the golden surface apart the hole. The electrical contact was made with a copper tape before placing the insulating tape.

Before each set of measurements, the surface of the Au-macro electrodes was cleaned electrochemically by cycling in $0.5 \mathrm{M}$ $\mathrm{H}_{2} \mathrm{SO}_{4}$ between -0.1 and $1.5 \mathrm{~V}$ at $100 \mathrm{mV} \mathrm{s}^{-1}$.

\section{Results and discussion}

\subsection{Electrochemical characterization and selection of the NEEs}

The Faradaic peak current at a NEE operating in the total overlap regime for a reversible redox system obeys the Randles-Sevcik equation [39]:

$I_{\mathrm{p}}=2.69 \times 10^{5} n^{3 / 2} A_{\text {geom }} D^{1 / 2} C^{*} v^{1 / 2}$

where $I_{\mathrm{p}}$ is the peak current (A), $A_{\text {geom }}$ the overall (nanoelectrodes + insulator between them) geometric area of the ensemble $\left(\mathrm{cm}^{2}\right), D$ the diffusion coefficient $\left(\mathrm{cm}^{2} \mathrm{~s}^{-1}\right), C^{*}$ the redox species bulk concentration $\left(\mathrm{mol} \mathrm{cm}^{-3}\right)$ and $v$ is the scan rate $\left(\mathrm{V} \mathrm{s}^{-1}\right)$.

At the same NEE, the double layer charging current $\left(I_{\mathrm{c}}\right)$ is proportional only to the area of the electrode elements (active area, $\left.A_{\text {act }}\right)[43,44]$ :

$I_{\mathrm{c}}=v C_{\mathrm{dl}} A_{\mathrm{act}}$

where $C_{\mathrm{dl}}$ is the double layer capacitance of the metal nanodisks of the NEE. Typical $I_{\mathrm{c}}$ values for the NEEs used in this work should be around $1 \mathrm{nA}$ (based on a $C_{\mathrm{dl}}$ value between 20 and
$40 \mu \mathrm{F} \mathrm{cm}^{-2}$ [42], a gold NEE with $A_{\text {geom }}=0.079 \mathrm{~cm}^{2}$, pore density $=6 \times 10^{8}$ pore $\mathrm{cm}^{-2}$, average pore radius $=2 \times 10^{-6} \mathrm{~cm}$, scan rate $\left.(v)=0.05 \mathrm{~V} \mathrm{~s}^{-1}\right)$.

From a practical viewpoint, the values given for the Faradaic peak currents and for the double layer charging currents calculated by Eqs. (1) and (2) can be used to discriminate between "good" and "bad" NEEs, the latter being NEEs with some defect which cause their voltammetric signals to differ from expected ones. In our laboratory, from a commercial PC nanoporous membrane of $47 \mathrm{~mm}$ diameter, we prepare a rather large number (typically around 30) of NEEs, which are then selected on the basis of the agreement between theoretical and experimental $I_{\mathrm{p}}$ and $I_{\mathrm{c}}$ values. The latter can be obtained from the cyclic voltammogram recorded in supporting electrolyte alone $[39,43]$ and the former by recording the $\mathrm{CV}$ in solution containing a known concentration of a reversible redox probe of known diffusion coefficient. From the CVs with and without the redox probe we select as "good NEEs" those that are characterized by $I_{\mathrm{p}(\exp )}=I_{\mathrm{p}(\text { theor })}(1 \pm 0.2)$ and $I_{\mathrm{c}(\exp )}=I_{\mathrm{c}(\text { theor })}(1 \pm 0.5)$, where $I_{\mathrm{p}(\exp )}$ and $I_{\mathrm{c}(\exp )}$ are the Faradaic peak currents and double layer charging currents measured experimentally, $I_{\mathrm{p}(\text { theor) }}$ and $I_{\mathrm{c} \text { (theor) }}$ are values calculated by Eqs. (1) and (2), respectively.

An even more practical way to rapidly distinguish good ensembles from bad ones is the comparison between experimental and digitally simulated CVs. Fig. 1 compares experimental voltammograms (dotted and dashed lines) recorded at "good" (part A) and "bad" NEEs (part B) with simulated ones (full line); the redox probe used is (ferrocenylmethyl)-trimethylammonium hexafluorophosphate $\left(\mathrm{FA}^{+} \mathrm{PF}_{6}^{-}\right)$, which is characterized by known reversible electrochemical behavior $[39,45]$. For the digital simulations the following parameters were used: $E^{0}=0.44 \mathrm{~V}$, $k^{0}=0.008$ and $D=4 \times 10^{-6} \mathrm{~cm}^{2} \mathrm{~s}^{-1}$ [46]. Note that $k^{0}$ is really the apparent rate constant $k_{\mathrm{app}}^{0}$; NEEs behave, in fact, as elec-
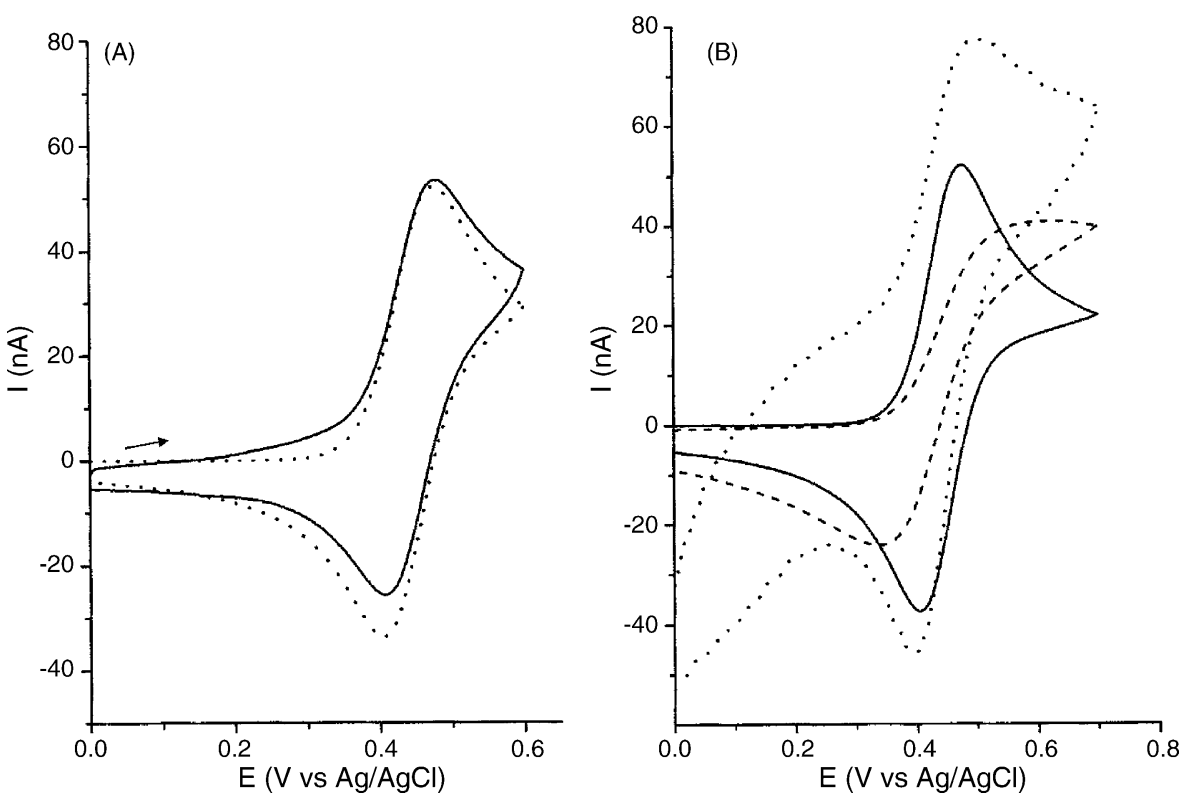

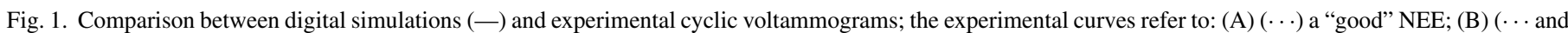

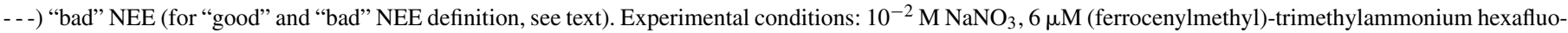

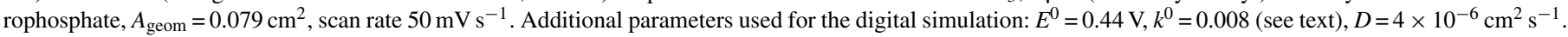


trodes with a partially blocked surface (PBE). According to the model developed by Amatore et al. [47], the current response at a PBE is identical to that at a bare electrode of the same overall geometric area but with a smaller apparent standard rate constant for the electron transfer which decreases with the porosity of the template membrane. Such an apparent rate constant $\left(k_{\text {app }}^{0}\right)$ is related to the true standard charge transfer rate constant $\left(k^{0}\right)$ and the fraction of blocked surface $(\vartheta)$ by the following relationship [47]:

$k_{\mathrm{app}}^{0}=k^{0}(1-\vartheta)$

Considering that $\vartheta=\left(A_{\text {geo }}-A_{\text {active }}\right) / A_{\text {geo }}$ [39], then Eq. (3) can be easily converted into

$k_{\mathrm{app}}^{0}=k^{0} f$

For the $\mathrm{FA}^{+}$case, $k^{0}=0.56$ [46] and $f=1.5 \times 10^{-2}$ [36].

"Good" NEEs should indeed display a satisfactory agreement between experimental and simulated CVs, as shown typically in Fig. 1A. The number of NEEs that satisfy this criterion ranges typically from 40 to $70 \%$ in a batch of NEEs obtained from just one PC membrane. On the other hand (see Fig. 1B), experimental CVs at "bad" NEEs will differ significantly from the simulated curves. Note that the experimental CVs in this latter figure show the features typical for two kinds of defects which can be produced during the preparation of NEEs. The dotted line voltammogram indicates that this NEE is affected by a large capacitive current, which was probably produced by poor sealing between the nanowires and the surrounding PC insulator and/or by heavy scratches or abrasions of the PC membrane caused by improper handling of the NEE. The poor sealing problem can be solved by heating the NEEs at $150{ }^{\circ} \mathrm{C}$ for $30 \mathrm{~min}$ [39]. The dashed line voltammogram shows a radial diffusive contribution to the overall signal and a current smaller than the theoretical one. This suggests larger distances between and a smaller number of nanoelectrode elements with respect to expected values, possibly as a consequence of the fact that not all the pores are filled by gold in the final NEE.

\subsection{Cyclic voltammetry of iodide}

Fig. 2 compares the cyclic voltammograms recorded in sulphuric acid, $\mathrm{pH} 1.0$, at an Au-macro electrode at iodide concentrations in the 50-70 $\mu \mathrm{M}$ range and at a NEE in the 5-7 $\mu \mathrm{M}$ range. The CVs are characterized by an oxidation peak with associated return peak both at the Au-macro and at the NEE. $E_{1 / 2}$ values, calculated as $\left(E_{\mathrm{pf}}+E_{\mathrm{pb}}\right) / 2$, where the f and b subscripts indicate the forward and backward peaks, respectively, were $0.548 \mathrm{~V}$ at the NEE and $0.524 \mathrm{~V}$ at the Au-macro; $\Delta E_{\mathrm{p}}$ values were of the order of $158 \mathrm{mV}$ at the NEE and $81 \mathrm{mV}$ at the Au-macro (both at $20 \mathrm{mV} \mathrm{s}^{-1}$ ). The observed peak system corresponds to the electrochemical oxidation of iodide [34] and following re-reduction in the reverse scan. By lowering the solution $\mathrm{pH}$ to $0\left(\mathrm{H}_{2} \mathrm{SO}_{4} 1 \mathrm{M}\right)$ at both electrode systems, $E_{1 / 2}$ values shift slightly to less positive values being $E_{1 / 2}=0.520 \mathrm{~V}$ at the $\mathrm{NEE}$ and 0.490 at the Au-macro, respectively.

As shown in Fig. 2, even if the $\mathrm{I}^{-}$concentration for the NEE measurements is one order of magnitude lower than at the Au-macro, the ratio between Faradaic (peak) currents and background currents are roughly comparable, in agreement with the lowering of capacitive (background) current which characterizes NEEs' responses [38,39]. At NEEs operating under total overlap diffusion conditions, capacitive currents scale with the active area (metal surface of the nanodisks electrodes) while the
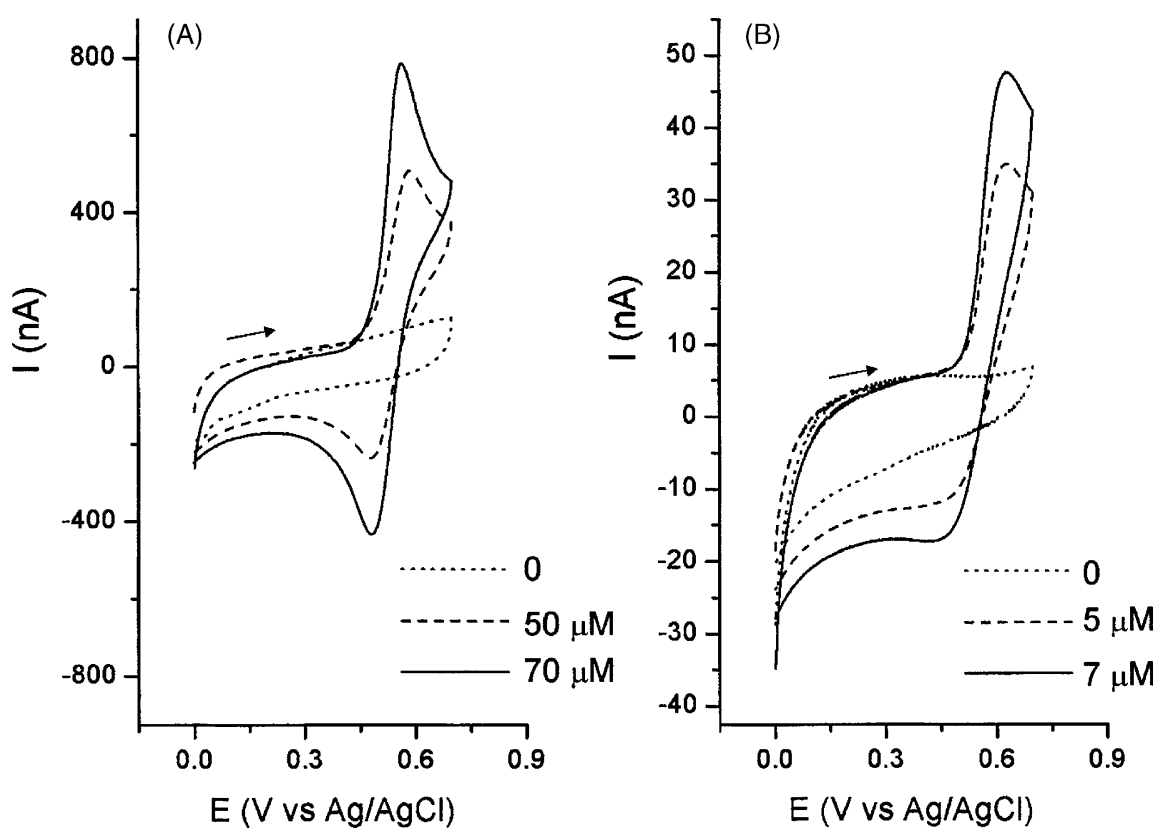

Fig. 2. Cyclic voltammograms recorded at different KI concentrations in sulphuric acid, pH 1.0: (A) at a Au-macroelectrode; (B) at a NEE. KI concentrations as indicated in the figure; scan rate $20 \mathrm{mV} \mathrm{s}^{-1}$, initial potential $0 \mathrm{~V}$, vertex potential $0.7 \mathrm{~V}$. 

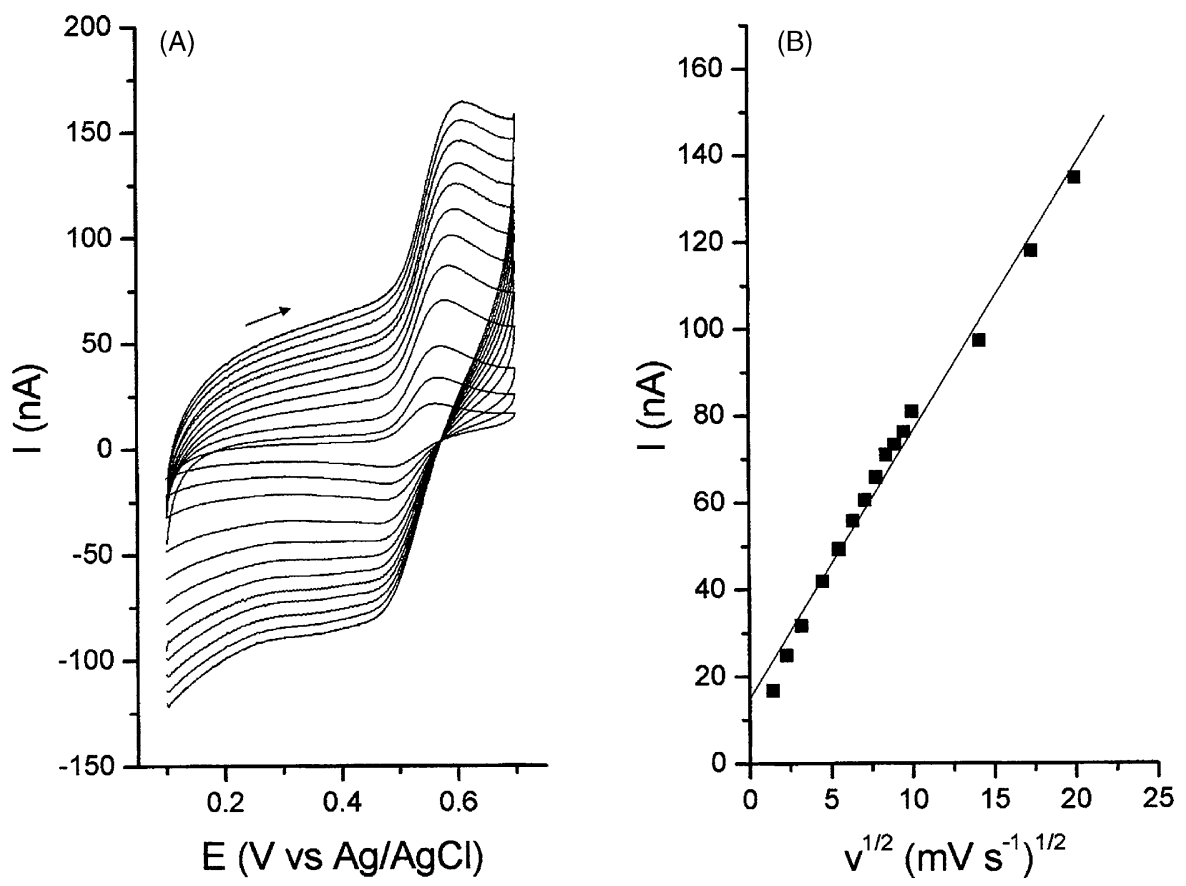

Fig. 3. (A) Cyclic voltammograms recorded at different scan rates (from 2 to $100 \mathrm{mV} \mathrm{s}^{-1}$ ) at a NEE in $5 \mu \mathrm{M} \mathrm{KI}$; (B) peak current dependence on the square root of the scan rate. Other conditons as in Fig. 2.

Faradaic current scales with the overall geometric area of the ensemble [37]; at the Au-macro both currents increase linearly with the geometric area [43].

As shown in Fig. 3, at the NEE, peak currents depend linearly on the square root of the scan rate, so indicating a process controlled by semi-infinite linear diffusion (typical for a NEE operating under total overlap conditions [39]); the same trend is observed at the Au-macro (not shown). Relevant voltammetric parameters measured at different scan rates at both kinds of electrodes in $1 \mathrm{M} \mathrm{H}_{2} \mathrm{SO}_{4}$, are listed in Table 1. These data put in evidence that, at both kinds of electrodes, $\Delta E_{\mathrm{p}}$ values increase with the scan rate. This might indicate a quasi-reversible electron transfer process, however, $E_{1 / 2}$ values shift towards more positive potentials with increasing scan rate so indicating the involvement of a more complex mechanism. Similar trends, however with proper adjustment in $E_{1 / 2}$ values (see above), are observed in $0.1 \mathrm{M} \mathrm{H}_{2} \mathrm{SO}_{4}$.

It is known, indeed, that iodide oxidation occurs via many steps in which adsorption-desorption process are involved; this was studied in detail for Pt electrodes [27-30] and for gold elec- trodes as well [31-34]. For the latter case, it was shown by Weaver and coworkers [34] that iodide electroxidation follows the pathway (where "ads" refers to an adsorbed species):

$2 \mathrm{I}^{-}($sol $)+\mathrm{I}^{-}(\operatorname{ads}) \rightarrow \mathrm{I}_{3}{ }^{-}(\operatorname{ads})+2 \mathrm{e}$

$2 \mathrm{I}^{-}(\mathrm{sol})+\mathrm{I}_{3}{ }^{-}($ads $) \rightarrow \mathrm{I}_{5}{ }^{-}($ads $)+2 \mathrm{e}$

and/or

$2 \mathrm{I}^{-}(\mathrm{sol})+\mathrm{I}^{-}($ads $) \rightarrow \mathrm{I}_{2} \cdots \mathrm{I}^{-}($ads $)+2 \mathrm{e}$

followed by

$\mathrm{I}_{5}{ }^{-}$(ads) $\rightarrow \mathrm{I}_{2}(\mathrm{sol})+\mathrm{I}_{3}{ }^{-}$(ads)

and/or

$\mathrm{I}_{2} \cdots \mathrm{I}^{-}($ads $) \rightarrow \mathrm{I}_{2}(\mathrm{sol})+\mathrm{I}^{-}($ads $)$

The electron transfer is indeed coupled with a series of chemical reaction involving both adsorbed and solution species. Increasing the scan rate causes a shift towards more positive potentials

Table 1

Cyclic voltammetric parameters at different scan rates $(v)$ at a NEE in $5 \mu \mathrm{M} \mathrm{KI}$, and at an Au-macro in $100 \mu \mathrm{M} \mathrm{KI}$; supporting electrolyte $1 \mathrm{M} \mathrm{H}_{2} \mathrm{SO}_{4}$

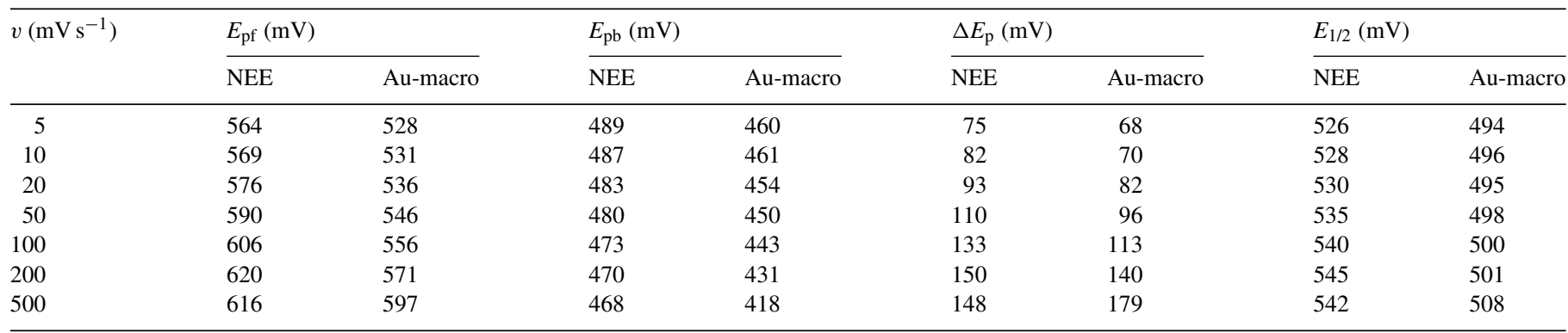



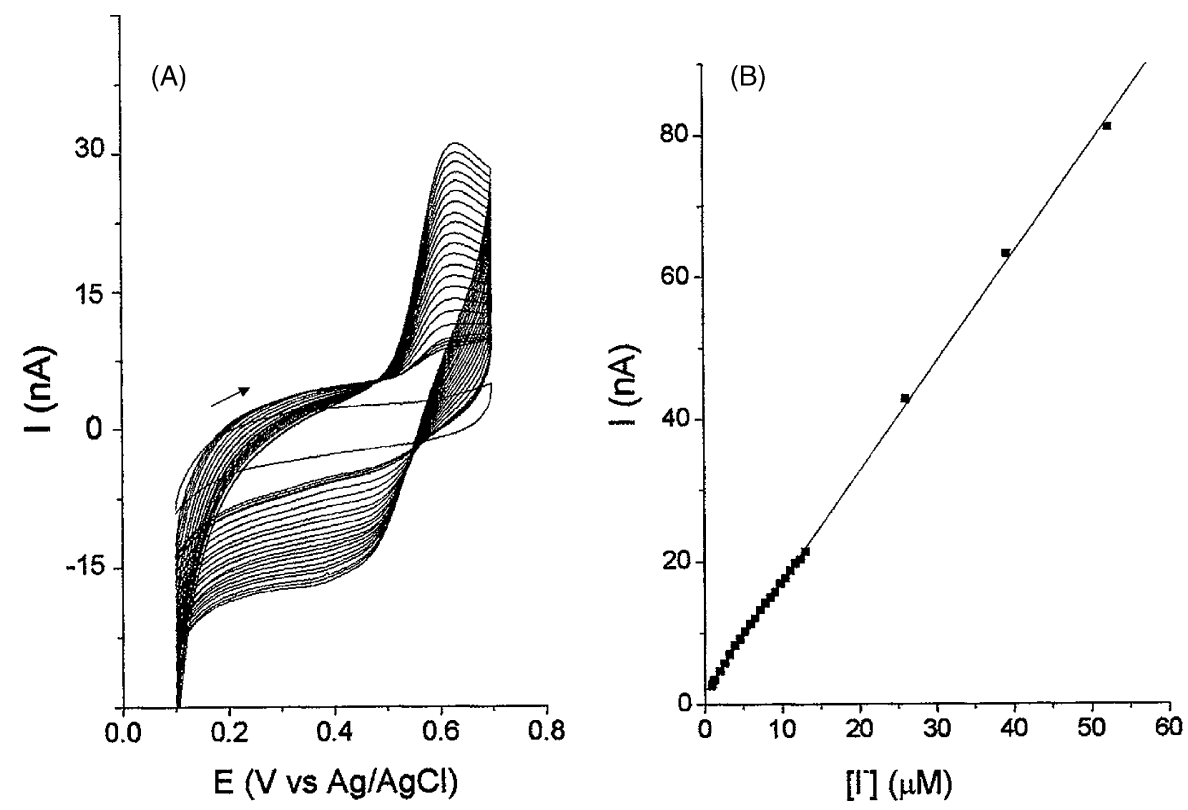

Fig. 4. (A) Cyclic voltammograms recorded at $20 \mathrm{mV} \mathrm{s}^{-1}$ at a $\mathrm{NEE}$ in sulphuric acid, $\mathrm{pH} 1.0$, at increasing $\mathrm{KI}$ concentrations (blank and then from 0.7 to $10 \mu \mathrm{M}$ ); (B) calibration plot.

because of the higher effect of the kinetics of the following chemical reactions (7) and (8) [43]. The slightly larger $\Delta E_{\mathrm{p}}$ values observed at NEEs, correspond anyway to the fact that the charge transfer at such nanoelectrode systems becomes apparently slower than at the Au-macro, since they behave like PBE (see Section 3.1).

Fig. 4 reports the concentration dependence and relevant calibration plot for the CVs recorded at NEEs at $20 \mathrm{mV} \mathrm{s}^{-1}$. The dynamic range extends over two order of magnitude with a sensitivity ( $m$, slope of the calibration plot) of $30 \mathrm{nA} \mathrm{cm}^{-2} \mu \mathrm{M}$. Replicate measurements of the blank current at $570 \mathrm{mV}$ gave a blank standard deviation $\sigma_{\mathrm{b}}$ of $0.03 \mathrm{nA}$, from which a detec- tion limit $\left(\mathrm{DL}=3 \sigma_{\mathrm{b}} / m\right)$ of $0.3 \mu \mathrm{M}$ was obtained. Such a DL is almost one order of magnitude lower than the best literature datum at gold ultramicroelectrodes [32]. Note also that data obtained by us at the Au-macro (see Fig. 5) is $4 \mu \mathrm{M}$, which is more than one order of magnitude higher than DL at NEEs. A relative precision of $\pm 2 \%$ was evaluated from the standard deviation of 15 repeated measurements at the same NEE dipped in a $5 \mu \mathrm{M}$ KI solution in sulphuric acid, $\mathrm{pH} 1.0$ and the reproducibility of voltammetric signals (in the same solution) within a batch of 10 different NEEs was $\pm 10 \%$. No preconcentration of iodide was employed in all these analyses.
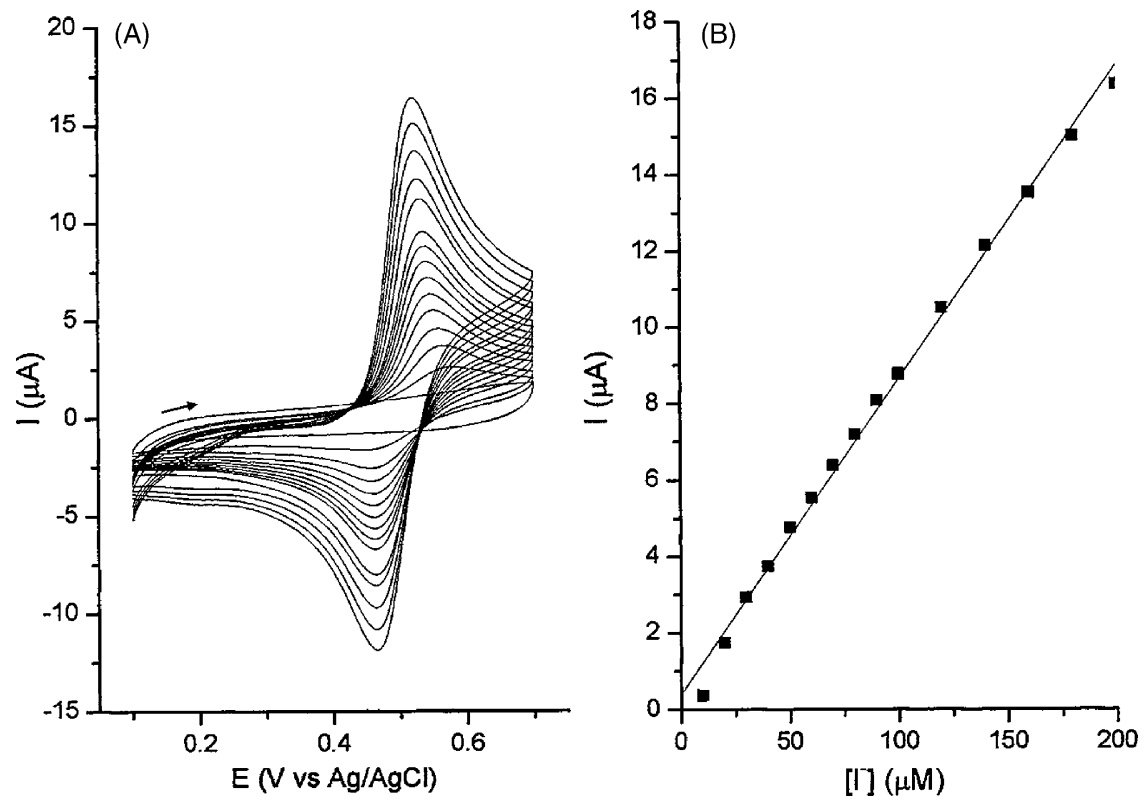

Fig. 5. (A) Cyclic voltammograms recorded at $20 \mathrm{mV} \mathrm{s}^{-1}$ at an Au-macro electrode in sulphuric acid, $\mathrm{pH}$ 1.0, at increasing KI concentrations (blank and then from 20 to $200 \mu \mathrm{M}$ ); (B) calibration plot. 

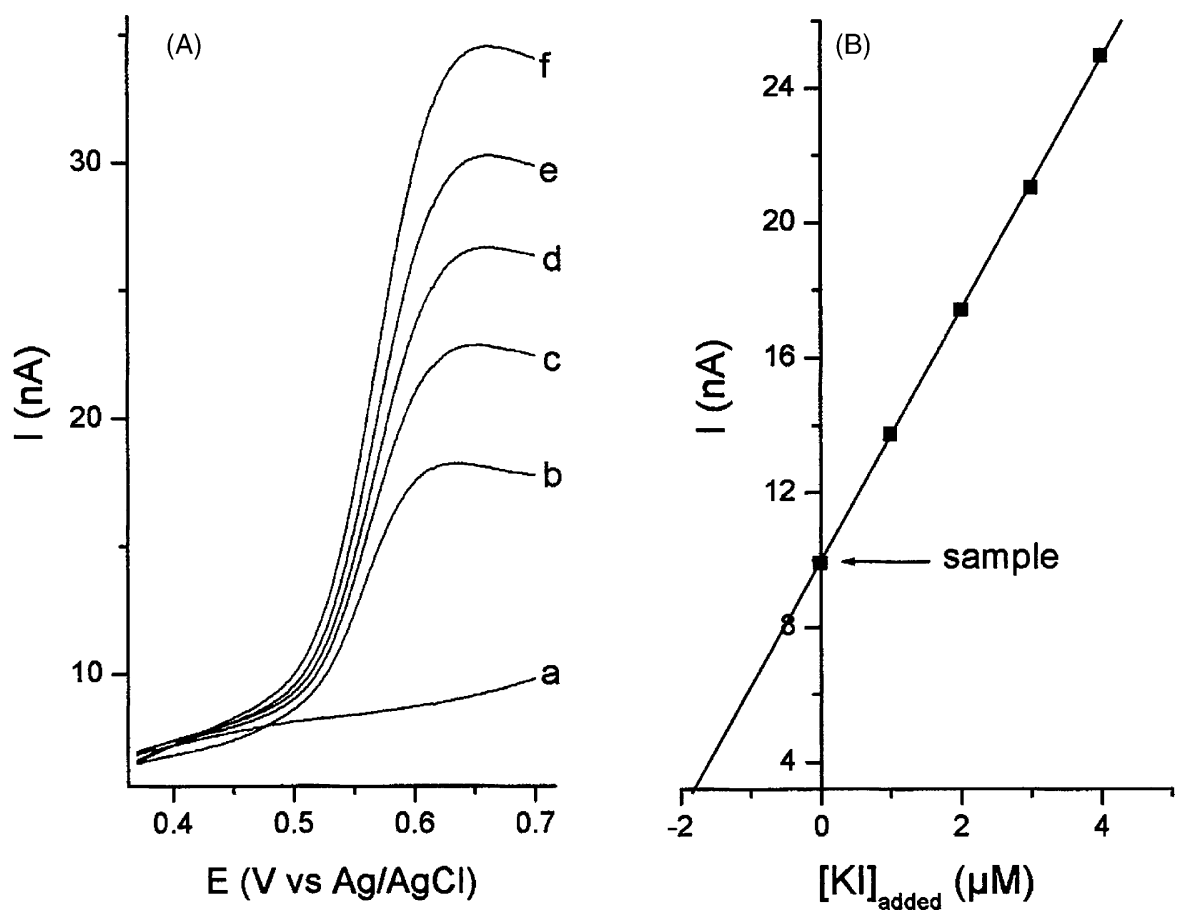

Fig. 6. (A) Linear sweep voltammograms recorded at $20 \mathrm{mV} \mathrm{s}^{-1}$ at a NEE in: (a) sulphuric acid, pH 1.0 (blank, $20 \mathrm{~mL}$ ); (b) spiked with $35 \mu \mathrm{L}$ of Facovit (pre-diluted 1:10) and after standard additions of KI: (c) $1 \mu \mathrm{M}$; (d) $2 \mu \mathrm{M}$; (e) $3 \mu \mathrm{M}$; (f) $4 \mu \mathrm{M}$. (B) Standard additions plot.

\subsection{Electroanalysis in real samples}

The above-developed method was tested for direct determination of iodide in two kinds of real samples: ophthalmic drugs and edible salt.

For the first application, the iodide content in two pharmaceutical preparations, namely Facovit and Rubjovit which are used for cataract therapy, was determined. To this aim, after recording a blank in sulphuric acid, $\mathrm{pH}$ 1.0, a small volume (see Section 2) of the Facovit drug was added and the voltammetric scan performed. As shown in Fig. 6A, a peak is observed at approxi-

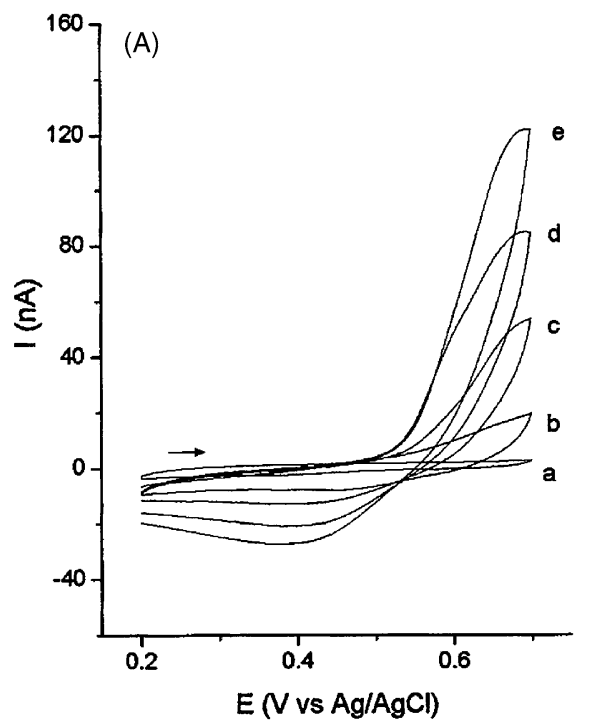

mately $0.620 \mathrm{~V}$, whose current increases with standard additions of KI. From the standard additions plot (see Fig. 6B), the concentration of iodide in the electrochemical cell (before the standard additions) was determined to be $1.9 \mu \mathrm{M}$. Three repeated analyses of the sample indicate that the average iodide concentration determined with the NEE was $1.9 \pm 0.1 \mu \mathrm{M}$; by taking into account sample dilution this agreed within $94.6 \%$ with the value expected on the basis of the iodide content declared by the producer, and within $98.4 \%$ with the result of a Volhard titration [48] performed in undiluted sample of the drug. Fully comparable results (not shown) with similar agreement between measured

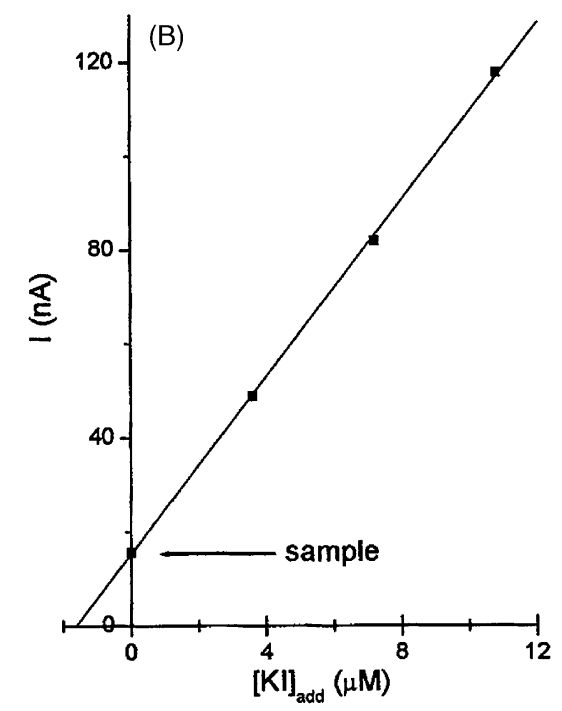

Fig. 7. (A) Cyclic voltammograms recorded at $20 \mathrm{mV} \mathrm{s}^{-1}$ at a NEE in: (a) sulphuric acid, $\mathrm{pH} 1.0$ (blank, $20 \mathrm{~mL}$ ); (b) spiked with $400 \mu \mathrm{L}$ of iodized table salt solution $\left(234 \mathrm{~g} \mathrm{~L}^{-1}\right)$ and after standard additions of $\mathrm{KI}$ : (c) $3.5 \mu \mathrm{M}$; (d) $7.0 \mu \mathrm{M}$; (e) $10.5 \mu \mathrm{M}$. (B) Standard additions plot. 
and declared iodide contents were obtained also for the other drug examined, namely Rubjovit, notwithstanding the different compositions of the two drugs examined.

The second application concerned with the determination of iodide in iodized table salt. As shown by the CVs in Fig. 7A, the voltammetric oxidation of $\mathrm{I}^{-}$in this kind of sample is slightly less reversible than in the previous ones (synthetic as well as pharmaceutical samples), however an oxidation peak is detected, whose current is proportional to the overall iodide content in the sample (see standard addition plot in Fig. 7B). At the dilution value used by us (namely, $[\mathrm{NaCl}] \approx 0.08 \mathrm{M}$ ) no interference from chloride was observed. The iodide concentration in the electrochemical cell, determined from triplicate analyses, was $1.6 \pm 0.3 \mu \mathrm{M}$. This value is smaller, but in acceptable agreement with the values of $2.1 \mu \mathrm{M}$ calculated from the iodide contents declared by the producer. Note that the iodine content declared for this kind of products is rather indicative; the initial amount of added iodide can, in fact, be lowered during storage as a consequence of partial volatilization following spontaneous oxidation of iodide to iodine $[4,49]$. The lower electrochemical reversibility of the CVs in these salt samples is probably due to other components, such as anticaking agents [50], which can be present in this rather complex sample. Anyway, the slight flattening of the peak currents does not inhibit the possibility to perform quantitative determinations, if the standard additions method is used.

\section{Conclusions}

Iodide is oxidised electrochemically both at gold macroelectrodes and at ensembles of gold nanodisk electrode. The detection limits are $0.3 \mu \mathrm{M}$ at NEEs and $4 \mu \mathrm{M}$ at Au-macro electrodes. Such an improvement in detection limits at NEEs, although relevant, is not as dramatic as in other applications, described previously $[36,37,39]$. This is related to the fact that iodide is an analyte difficult to determine at NEEs, since its oxidation takes place at potential values quite close to the oxidation limit of the potential window accessible at this kind of nanoelectrodes [39]. Note that such an increase in DL for species which are electroactive at potentials approaching the limit of the potential window accessible at NEEs, was observed before, however for the case of reduction processes [35].

In any case, the results presented here show that the use of gold NEEs allows the direct determination of micromolar and even submicromolar concentrations of iodide by simple cyclic voltammetry, without requiring any preceding preconcentration of the analyte. This direct method of analysis can be applied successfully to the determination of iodide in pharmaceutical products and iodized edible salt.

\section{Acknowledgements}

Financial support by MIUR/Rome (Cofin 2004) is gratefully acknowledged. FCP is thankful to Capes (Brazil) for an international mobility grant. We thank Dr. Martina Zamuner and Dr. Federica Minto for assistance in some experiments.

\section{References}

[1] P. Pongpaew, S. Saowakontha, R. Tungtrongchitr, U. Mahaweerawat, F.P. Schelp, Nutr. Res. 22 (2002) 137.

[2] F. Delange, B. de Benoist, D. Alnwick, Thyroid 11 (2001) 437.

[3] F. Delange, B. de Benoist, D. Alnwick, Thyroid 9 (1999) 545.

[4] K. Muranov, N. Poliansky, R. Winkler, G. Riegerm, O. Schmut, J. Horwat-Winter, Graefes Arch. Clin. Exp. Ophthalmol. 242 (2004) 146.

[5] E.F. Elstner, R. Adamczyk, A. Furch, R. Kroner, Ophthalmic Res. 17 (1985) 302.

[6] J.L. Lambert, G.L. Hatch, B. Mosier, Anal. Chem. 47 (1975) 915.

[7] M. Haldimann, B. Zimmerh, C. Als, H. Gerber, Clin. Chem. 44 (1998) 817.

[8] K. Ito, T. Ichihara, H. Zhuo, K. Kumamoto, A.R. Timerbaev, T. Hirokawa, Anal. Chim. Acta 497 (2003) 67.

[9] K. Yokota, K. Fukushi, S. Takeda, S.I. Wakida, J. Chromatogr. A 1005 (2004) 145.

[10] G.T. Wong, P.G. Brewer, Anal. Chim. Acta 81 (1976) 81.

[11] K. Ito, J. Chromatogr. A 830 (1999) 211.

[12] W. Kemula, Z. Kublik, J. Taranszewski, Microchem. J. Symp. Ser. (1962) 2.

[13] J. Perchard, M. Buvet, R. Molina, J. Electroanal. Chem. 14 (1967) 57.

[14] R.C. Propst, Anal. Chem. 49 (1977) 1199.

[15] K.Z. Brainina, Fresenius Z. Anal. Chem. 312 (1982) 428.

[16] G.W. Luther, C.B. Swartz, W.J. Ullman, Anal. Chem. 60 (1988) 1721.

[17] L. Rong, T. Takeuchi, J. Chromotogr. A 1042 (2004) 131.

[18] I. Shain, S.P. Perone, Anal. Chem. 33 (1961) 325.

[19] T. Nomura, T. Mimatsu, Anal. Chim. Acta 143 (1982) 237.

[20] T. Nomura, M. Watanabe, T.S. West, Anal. Chim. Acta 175 (1985) 107.

[21] R.D. Rocklin, E.J. Johnson, Anal. Chem. 55 (1983) 4.

[22] L. Liang, Y. Cai, S. Mou, J. Cheng, J. Chromatogr. A 1085 (2005) 37.

[23] L. Guangam, Y. Min, Z. Qifang, W. Ailan, J. Zexiang, Electroanalysis 7 (1995) 591

[24] I. Svancara, J. Konvalina, K. Schachl, K. Kalcher, K. Vytras, Electroanalysis 10 (1998) 435 .

[25] A. Walcarius, G. Lefevre, J.-P. Rapin, G. Renaudin, M. Francois, Electroanalysis 13 (2001) 313 .

[26] F.C. Pereira, A.G. Fogg, P. Ugo, E.P. Bergamo, N.R. Stradiotto, M.V.B. Zanoni, Electroanalysis 17 (2005) 1309

[27] R.A. Osteryoung, F.C. Anson, Anal. Chem. 36 (1964) 975

[28] A.T. Hubbard, R.A. Osteryoung, F.C. Anson, Anal. Chem. 38 (1966) 692.

[29] E.C. Toren, C.P. Driscoll, Anal. Chem. 38 (1966) 873.

[30] S. Swathirajan, S. Bruckenstein, J. Electroanal. Chem. 112 (1980) 25.

[31] T. Bejerano, E. Gileadi, J. Electroanal. Chem. 82 (1977) 209.

[32] W. Zhang, H. Zha, B. Yao, C. Zhang, X. Zhou, S. Zhong, Talanta 46 (1998) 711.

[33] P. Gao, M.J. Weaver, J. Phys. Chem. 90 (1986) 4057.

[34] M.A. Tadayyoni, P. Gao, M.J. Weaver, J. Electroanal. Chem. 198 (1986) 125 .

[35] B. Brunetti, P. Ugo, L.M. Moretto, C.R. Martin, J. Electroanal. Chem. 491 (2000) 166.

[36] P. Ugo, N. Pepe, L.M. Moretto, M. Battagliarin, J. Electroanal. Chem. 560 (2003) 51.

[37] L.M. Moretto, N. Pepe, P. Ugo, Talanta 62 (2003) 1055.

[38] P. Ugo, L.M. Moretto, F. Vezzà, Chemphyschem 3 (2002) 917.

[39] V.P. Menon, C.R. Martin, Anal. Chem. 67 (1995) 1920.

[40] M. Delvaux, S. Demoustier-Champagne, A. Walcarius, Electroanalysis 16 (2004) 190.

[41] M. Delvaux, A. Walcarius, S. Demoustier-Champagne, Biosens. Bioelectron. 20 (2005) 1587.

[42] A. Lombardo, T.I. Bieber, J. Chem. Educ. 60 (1983) 1080.

[43] A.J. Bard, L. Faulkner, Electrochemical Methods, Wiley, New York, 2000. 
[44] R. Greef, R. Peat, L.M. Peter, D. Pletcher, J. Robinson, Instrumental Methods in Electrochemistry, Ellis Horwood, Chichester, UK, 1985.

[45] P. Ugo, L.M. Moretto, S. Bellomi, V.P. Menon, C.R. Martin, Anal. Chem. 68 (1996) 4160.

[46] E. Sabatani, J. Rubinstein, J. Phys. Chem. B 91 (1987) 6663.

[47] C. Amatore, J.M. Saveant, D. Tessier, J. Electroanal. Chem. 147 (1983) 39.
[48] A.I. Vogel, A Textbook of Quantitative Inorganic Analysis, 3rd ed., Longman, London, UK, 1961, p. 267.

[49] I. Svancara, B. Ogorevc, M. Novic, K. Vytras, Anal. Bioanal. Chem. 372 (2002) 795.

[50] J. Holman, Boletin de la Oficina Sanitaria Panamericana, Febrero (1966) 139. 